\title{
LA MAYOR OBRA DE PICASSO EN BARCELONA: LOS FRISOS ESGRAFIADOS DEL COLEGIO DE ARQUITECTOS
}

\section{Joan Bassegoda i Nonell}

La bibliografía sobre Picasso es extensa, prolija y reiterativa. Jacobus Sabartés, su amigo devoto y fiel secretario, dejó escrita una importantísima biografía, en 1941, que sirve para comprender el carácter de este artista genial a la par que su personalidad humana llena de contrastes y paradojas ${ }^{2}$.

Llegado a Barcelona en 1895, del brazo de su padre el profesor de Bellas Artes, José Ruiz Blasco, estudió en la Escuela de Lonja y realizó hasta 1903, en que marchó a París para no volver a Barcelona, una obra de gran valor y fuerza. Este período de Picasso en Barcelona fue comentado con gran acierto por el arquitecto, pintor y crítico de arte José Francisco Ràfols Fontanals en un escrito de 1955 que se publicó el 3 de marzo del año siguiente en la revista Destino ${ }^{3}$. El motivo de tal artículo era sumarse a la Exposición Retrospectiva sobre Picasso comprendida en la III Bienal Hispano-Americana de Arte que se celebró en el palacio la Virreina en la Rambla barcelonesa en 1955.

Precisamente en la Rambla y en el comedor del Círculo del Liceo, Picasso había sido investido oficialmente como pintor en el curso de un almuerzo en 1897 en el que el crítico Joaquín Martínez de la Vega derramó, a modo de bautismo artístico, unas gotas de champán sobre la cabeza de aquel muchacho de 16 años que había ganado una mención honorífica por el óleo Ciencia y Caridad en la Exposición Nacional de Bellas Artes en mayo de $1896^{4}$.

En febrero de 1900 celebró Pablo Ruiz Picasso su primera exposición individual en la sala Els Quatre Gats que mereció elogios de, por lo menos tres críticos, en La Vanguardia, Diario de Barcelona y La Renaixensa. En este último periódico, con fecha 10 de febrero de 1900, el arquitecto Buenaventura Bassegoda Amigó opinó que el pintor a pesar de pertenecer a la escuela novísima impresionista, reúne condiciones que no todos los sectarios de ella suelen ofrecer, facilidad y corrección en el dibujo y un cierto instinto del color 5 .

\footnotetext{
I SABARTÉS, J.: Picasso. Portraits et souvenirs. Louis Carré et Maximilen Vox, Genève, 1941. (edición española: Picasso. Retratos y recuerdos. Afrodisio Aguado, Madrid, 1953).

2 BASSEGODA I NONELL, J.: "Picasso i l'estudi de Jacobus Sabartés", Butlletí X, Reial Acadèmia Catalana de Belles Arts de Sant Jordi, Barcelona, 1996, págs. 259-262.

3 RÀFOLS, J.F.: "La etapa barcelonesa de Picasso", Destino, Barcelona, 3 de marzo de 1956.

${ }^{4}$ BASSEGODA I NONELL, J.: Un centenario picassiano. Memoria del Círculo del Liceo, Barcelona, $2-13$

${ }^{5}$ FONTBONA, F.: “ Bonaventura Bassegoda, crític i historiador de l'art”, en La obra arquitectónica de Pere, Joaquim i Bonaventra Bassegoda (1856-1934), Reial Academia Catalana de Belles Arts de Sant Jordi, Barcelona, 1995, págs. 13-17.
} 
En Barcelona quedaron muy buenas obras suyas, primero en el Museo de Arte Moderno del parque de la Ciudadela y luego, junto con el legado Sabartés, la colección Vilató y la serie de las Meninas, en el Museo Picasso del palacio Berenguer de Aguilar de la calle de Montcada, restaurado por el arquitecto Adolfo Florensa Ferrer por impulso del alcalde de Barcelona José María de Porcioles Colomer.

De todas maneras la mayor obra de Picasso en Barcelona no se realizó hasta 1960 en los muros del nuevo edificio del Colegio Oficial de Arquitectos de Cataluña y Baleares en la plaza Nueva, proyectado y dirigido por el arquitecto Javier Busquets Sindreu (1917-1990).

En mayo de 1955 el Colegio de Arquitectos decidió construir una nueva sede social dejando la que tuvo en la Gran Vía, esquina pasaje Valerio Serra Boldú, en un edificio proyectado y legado testamentariamente a la Asociación de Arquitectos de Cataluña por el arquitecto Buenaventura Pollés Vivó. Se convocaron dos concursos entre arquitectos en 1956 y 1958 y en ambos venció Javier Busquets.

Busquets ganó su título de arquitecto en 1947 después de una azarosa carrera iniciada a poco de terminada la guerra civil, en la que había participado en el ejército nacional como piloto de la escuadrilla García Morato, lo que le valió diversas condecoraciones, la Laureada Colectiva y la Medalla de Oro de la Ciudad de Barcelona. Apenas iniciados sus estudios en la Escuela de Arquitectura, se alistó en la Escuadrilla Azul que combatió en Rusia pilotando un caza Messerschmit 109 con el que llegó a sobrevolar Moscú. Recibió la Cruz de Hierro de segunda clase que le impuso el coronel von Richthofen y también la de primera clase de mano del mariscal Kesselring. Tales hechos demuestran la manera de ser de Busquets, inquieto, dinámico y a la vez culto, políglota y gran coleccionista de obras de arte, para el que tenía un gusto exquisito, heredado de su padre el también arquitecto y urbanista Guillermo Busquets Vautravers. Acabada la carrera marchó en 1951 a Brasil, capital entonces de la arquitectura de vanguardia y, en Sao Paulo trabajó con sus colegas Lukjan Korngold y Franz Heep, éste discípulo de Le Corbusier. En 1955, junto con Heep ganó el gran Premio de Arquitectura en la III Bienal de Arte Hispanoamericano celebrada en Barcelona, la misma en la que se presentó la exposición antológica de Picasso, más arriba referida.

En 1964 levantó la sede central de Hispano Olivetti en Madrid, en 1968 la de Sandoz en Barcelona, en 1972 el edificio ahora de la Caja de Pensiones en la Diagonal, 519, en 1974 la Mutua de Seguros en Diagonal-Entenza, la sede de la Societé General de Banque en la plaza de Catalunya y en 1982 la Escuela Superior de Empresas, ESADE, en la avenida de Pedralbes, entre otras destacadas obras dentro y fuera de Barcelona 6 .

\footnotetext{
${ }^{6}$ La colección de proyectos de Javier Busquets se conserva en el Archivo Histórico del Colegio de Arquitectos de Cataluña en Barcelona.
} 
El 9 de diciembre de 1987 leyó su discurso de ingreso en la Real Academia Catalana de Bellas Artes de San Jorge que fue contestado por el autor de este texto, que consideró tal tarea como un alto honor y una gran satisfacción. Participó Busquets en las tareas académicas pero con poca intensidad por causa de la enfermedad que lo llevó a la muerte en su casa de la calle Duquesa de Orleans el 15 de agosto de 1990, a los setenta y tres años de edad. Su casa era un maravilloso museo que donó al monasterio de Montserrat. Figuran once piezas del Egipto faraónico, siete del mundo clásico y 53 de arte moderno con obras de Regoyos, Nonell, Mir, Torres García, Dalí, Miró, Clavé, Hugué, Pissaro, Monet, Sisley, Degas, Poliakoff, Roualt, Gris, Metzinger, Marini, Braque, Le Corbusier y nada menos que veinte Picassos, varios de ellos dedicados.

Esta simple enumeración da idea de la gran colección del arquitecto que, además, contenía obras de arte de Benin, de Ifé, de la India, muebles holandeses, tallas góticas y vidrieras medievales?

El discurso de ingreso de Busquets en la Academia de San Jorge versó sobre la decoración exterior e interior del edificio del Colegio de Arquitectos mediante la técnica del esgrafiado.

Las obras del colegio se iniciaron en mayo de 1959 y fue inaugurado en 1962. En la planta primera está la sala de actos de forma trapezoidal y muros ciegos. Para la decoración exterior de estos muros Busquets había pensado en un alicatado cerámico de gres de Antonio Comella. Las cosas fueron por otro camino. En tanto la decoración interior de los dos muros laterales de la sala de actos quedó por decidir.

Años antes Busquets conoció a Picasso en Cannes a través del amigo común Jacinto Raventós. Fue Busquets amablemente recibido por Picasso en La Californie y el pintor se interesó mucho por lo que se hacía entonces en Barcelona. De aquella visita recordaba el arquitecto la impresión inalterable de unas manos honradas y unos ojos de curiosidad implacable, corregida por la experiencia.

En octubre de 1958 viajó Busquets a París, mientras redactaba el proyecto del Colegio de Arquitectos y visitó el edificio de la UNESCO, viendo el mural de Juan Miró con la cerámica de José Llorens Artigas, que le sugirió una posible colaboración Picasso-Cumella para el edificio en proyecto. A través del editor Gustavo Gili, Busquets consiguió ver de nuevo a Picasso, cosa que hizo provisto de planos, perspectivas y fotografías de maquetas, junto con otras fotos referidas a manifestaciones populares de Barcelona, así como una película sobre la Feria de Santa Lucía de Barcelona, las torres humanas de los Xiquets de Valls y la procesión de Corpus Christi, con sus gigantes y cabezudos. La idea era sugerir motivos decorativos al pintor, sin tratar, como es lógico, de influir en su proceso creativo. Picasso vio y calló. Luego el resultado de la idea de Picasso, creía Busquets, fue una especie de

7 SALAMERO, A. y TAPIA, L.: Donació de Xavier Busquets al Museu de Montserrat (inèdit), Arxiu de la Reial Càtedra Gaudí. 


\section{Joan Bassegoda i Nonell}

recreación anecdótica de lo que vio en planos y películas y de lo que, con prodigiosa memoria, recordaba de Barcelona.

Picasso rechazó la idea del alicatado cerámico y dispuso la utilización de un sistema nuevo por entonces, del que tenía buen recuerdo de unos dibujos suyos del museo Grimaldi de Antibes reproducidos en el edificio del Gobierno noruego en Oslo. La técnica empleada era trazar líneas de dibujo con chorro de arena a presión que descarna, graba y erosiona la capa lisa del hormigón en proceso de fraguado, formando rugosidades, perfiles y relieves. Marchó Busquets, impenitente viajero, a Oslo y conoció a su colega Erling Viksjö, autor del edificio del gobierno entre 1956 y 1958, y al pintor, escultor y fotógrafo Carl Nesjar, especialista en el esgrafiado sobre hormigón tierno.

Busquets empezó a considerar el nuevo sistema y pensó que sería más llamativo si la línea del chorro de arena fuera de color distinto al del muro. Decidió que lo mejor era utilizar grava de color negro embebida mortero de cemento blanco para que el esgrafiado dejara vista una línea negra en una superficie blanca, igual que lápiz sobre el papel.

Nesjar conocía a Picasso y era un personaje realmente digno del malagueño. Un hombretón nórdico, alto, cepado y barbudo, con una gorra marinera de lana y unas tremendas botas de cuero. Tenía una energía vital enorme y quiso invitar al arquitecto a la caza de ballenas que practicaba en una lancha desde la cual disparaba personalmente el arpón. Nesjar fue a Barcelona para hacer pruebas de la variante del sistema de chorro de arena, con mortero blanco y piedra negra o piedra negra y cemento blanco. Se fotografiaron las pruebas y se presentaron a Picasso que escogió el sistema de fondo blanco, entre cosas porque la piedra negra es más resistente al chorro de arena.

Se extrajeron grandes piedras volcánicas de basalto de San Joan les Fonts (La Garrotxa, Gerona), se trituraron en la machacadora y luego se pulieron rodándolas durante diez horas en un molino de bolas.

Mientras la obra no podía iniciarse pues aún no se disponía de los croquis de Picasso. Sabiendo el trabajo que tenía el pintor, Busquets trató de convencerlo visitándolo una vez por mes y llamándole cada semana por teléfono para tenerlo bien enterado del proceso. Es preciso decir que Busquets llegó a visitar a Picasso hasta sesenta veces, cosa que muchos de sus biógrafos no consiguieron, ni de lejos. Pero su proverbial modestia le permitió no alardear nunca de su intensa relación con Picasso y toda la historia de la decoración del Colegio de Arquitectos, Busquets solo la contó una vez, en su recepción en Academia de San Jorge, casi treinta años después, y únicamente se ha publicado en su discurso de ingreso, en catalán, con un tiraje de 400 ejemplares o menos ${ }^{8}$.

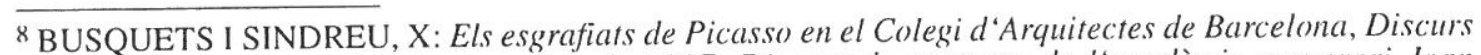
de l'acadèmic electe el 9 de desembre de 1987, Discurs de contesta de l'acadèmic numerari Joan Bassegoda Nonell, Reial Academia Catalana de Belles Arts de Sant Jordi, Barcelona, 1987. 
En una de las visitas llevó los bastidores con la tela debidamente montada de los tres paramentos del Colegio de Arquitectos a escala 1:10. Cuando los vio y los palpó Picasso dijo que en su vida había tenido bastidores tan buenos. Los había tallado el carpintero y ebanista Jaime Gurt del barrio de Gracia de Barcelona.

Un día al despedirse de Picasso y de Jacqueline el arquitecto le dijo que no podían demorar más la confección de los esgrafiados ya que el edificio estaba casi listo. Picasso contestó de la siguiente y por demás curiosa manera: "Reza un Padrenuestro para que te lo haga". Poco después, el 18 de octubre de 1960, a las once de la noche, Picasso llamó por teléfono al arquitecto para decirle que los croquis estaban listos y que fuera a recogerlos personalmente. Excusado es decir que Busquets había rezado con gran fe y, desde luego, más de un Padrenuestro. El 20 de octubre de 1960, a la una del mediodía en el taller de Picasso, vio por primera vez los dibujos hechos al carboncillo sobre la tela de los bastidores. Medían $232 \times 43 \mathrm{~cm}$. el friso de los niños, 112,5 × 43 el de los gigantes y 255 × 43 el de la bandera.

Los esbozos de Picasso para las tres fachadas del Colegio de Arquitectos presentan, en el chaflán frente a la plaza Nueva, dos gigantes coronados que flanquean un grupo de chiquillos que portan ramas de árbol en la mano. A la Izquierda un caballero y a la derecha dos niños más con ramas en la mano. Observando la composición se comprende que no corresponde a un tema único, ya que los gigantes salen en la procesión del Corpus Christi, pero los niños con palmas o ramas son propios del Domingo de Ramos. Se ha pensado también que el grupo central sea la Moixiganga de Sitges o grupo de jóvenes montando una pirámide en cuya cúspide uno de ellos lleva una tea encendida.

En el friso de la calle Capellans hay dos caballeros, el segundo de los cuales lleva una especie de gonfalón o estandarte seguidos de varios músicos, dos de ellos sonando la flauta doble o caramillo pánico y los restantes con címbalos, siguen un toro llevado del ronzal por un chiquillo, tres cimbalistas más y una barca con vela latina.

En la calle Arcs aparece en primer lugar una barca de vela cuadrada, cuatro cimbalistas, tres niños cogidos de la mano y otros dos flautistas. Los dos laterales no tienen relación alguna con las fiestas de Corpus Christi o el Domingo de Ramos y presentan un aspecto claramente pagano propio de las fiestas saturnales, bacanales o pánicas, tema que en varias ocasiones sedujo a Picasso.

Con los modelos en Barcelona, modelos que por cierto al final se quedó Picasso, se inició el trabajo. Sobre el cerramiento exterior del salón de actos se prepararon las placas de hormigón de $11 \mathrm{~cm}$. de espesor, en piezas de 4 a $5 \mathrm{~m}$. de longitud. De esta manera se podía actuar sobre hormigón aun no fraguado. Las placas interiores miden 9,75 × 3,10 y 8,5 x 3,10 respectivamente y están situadas en los paramentos laterales interiores de la antesala de actos.

Se montaron los encofrados cerrados lateralmente con yeso y se fueron llenando de piedras que se apisonaban a mano por tongadas sucesivas. 


\section{Joan Bassegoda i Nonell}

El mortero se hizo a base de cemento blanco Griffi y arena en igual proporción en tanto que la relación agua cemento fue de 0,46 . La arena era silícea de grueso de un milímetro, el $80 \%$, procedente de Soria ,de dos milímetros, el 14\%, de Valencia y el $6 \%$ restante de menos de un milímetro. Una vez el encofrado estuvo lleno de grava negra se introdujo el mortero por inyección, reforzando fuertemente el encofrado pues la presión era muy fuerte, para que el mortero se distribuyera uniformemente por toda la placa.

Exteriormente el encofrado se cerró con placas de plástico Fórmica para obtener una superficie totalmente lisa. El inconveniente fue que al desencofrar apareció la superficie brillante por lo que hubo que tratarla con ligero chorro de arena. Al cabo de 48 horas se desencofraron los paramentos.

Para proceder al esgrafiado se habían preparado previamente los estarcidos, es decir unos papeles de embalar del tamaño natural de los dibujos. Para ello se colgaban los papeles de un muro en un almacén del barrio de Las Corts y se proyectaban diapositivas desde diez metros de distancia de los dibujos originales. Se reseguían con pincel las proyecciones sobre el papel y luego se perforaban con un punzón. Se llevaban los estarcidos al edificio y se fijaban sobre los muros. Nesjar, con la clásica bolsita de tela llena de grafito, reseguía los trazos dibujados que quedaban marcados sobre el hormigón tierno. Luego con los originales a la vista perfilaba los trazos con lápiz de cera.

Entonces empezó la tarea del esgrafiado con el chorro de arena habiendo protegido el lugar con lonas y ventiladores que proyectaban la enorme polvareda contra una de las lonas empapada en agua. Nesjar trabajaba con una máscara antigás que le daba singular e impresionante aspecto.

El rebote de la arena sobre los cristales de la máscara los rompía por lo que había que cambiarlos con mucha frecuencia. Los esgrafiados exteriores quedaron listos pero había que pensar en los muros interiores a decorar. Busquets pensó en pedir los esbozos a Juan Miró, cosa que consultó con Picasso que le dijo de sopetón: Los Miró te los haré yo. En poco tiempo terminó los dos croquis y de nuevo fue Busquets a recogerlos a Francia. Forman el mural de los arcos de 168 x $62 \mathrm{~cm}$. y el de la sardana de 183 × 62 a escala 1:15. En el de ellos se ve, a través de unos arcos un castillo junto a un puerto de mar y en otro la avenida del Paralelo con Montjüic al fondo y, a continuación una especie de acueducto. En comparación con el movimiento representado en los frisos exteriores, este muro se muestra estático. En frente el paramento presenta una composición única en la que pueden ver dos sardanas concéntricas, con la de los niños en el interior.

Busquets comentó en su discurso que los trazos simples en los frisos del Colegio de Arquitectos son un verdadero esfuerzo de síntesis hecho por un artista de ochenta años tras una larga vida de búsqueda de las formas íntimas del arte.

Los esgrafiados del Colegio de Arquitectos no solo son la mayor obra de Picasso en Barcelona, sino la única que hizo en España después de 1936. podría 
pensarse que su ideario político le impedía trabajar para la España de entonces, pero el arte y los artistas han estado siempre por encima de la política. Prueba de ello es la entrega de innúmeras obras al Museo Picasso de Barcelona y la realización de los esgrafiados del Colegio de Arquitectos.

El tema de los esgrafiados no ha sido tratado en profundidad más que por Javier Busquets ya que un libro de Alejandro Cirici Pellicer de 1956 es solamente un cuaderno de comentarios conceptuales sin pormenores técnicos ${ }^{9}$.

Por cierto, que una vez que este autor habló con Picasso le contó los antecedentes bélicos de Busquets, miembro de la escuadrilla García Morato y de la División Azul. Picasso se limitó a encogerse de hombros y no hizo comentario alguno. Además de artista, Picasso era un señor.

${ }^{9}$ CIRICI PELliCER, A.: Esgrafiados de Picasso en el Colegio de Arquitectos de Cataluña y Baleares, Publicaciones del COACB, Barcelona, 1965. 


\section{Joan Bassegoda i Nonell}

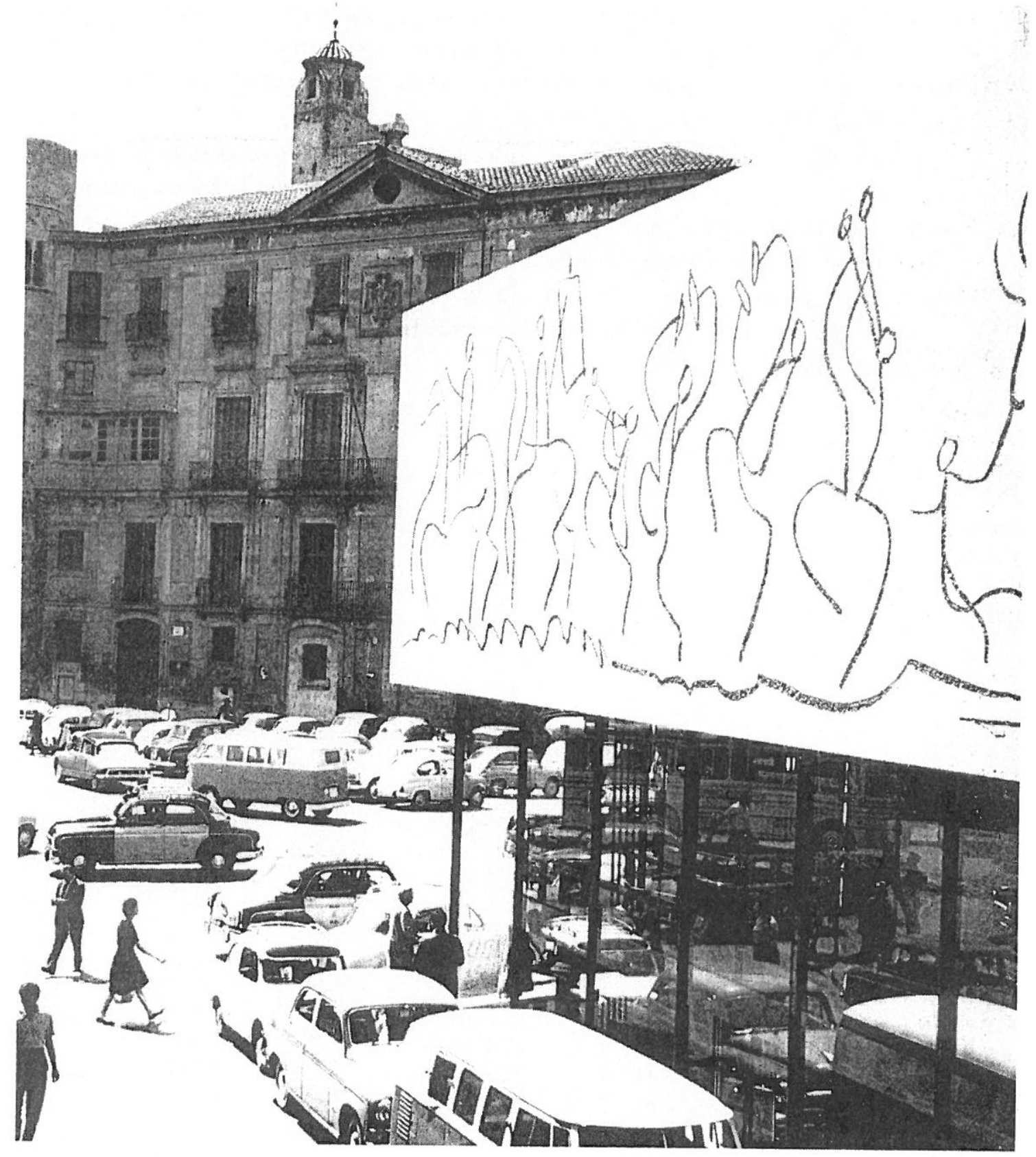

1.- Friso esgrafiado de la calle Capellans. Al fondo el Palacio Arzobispal. 
La mayor obra de Picasso en Barcelona...

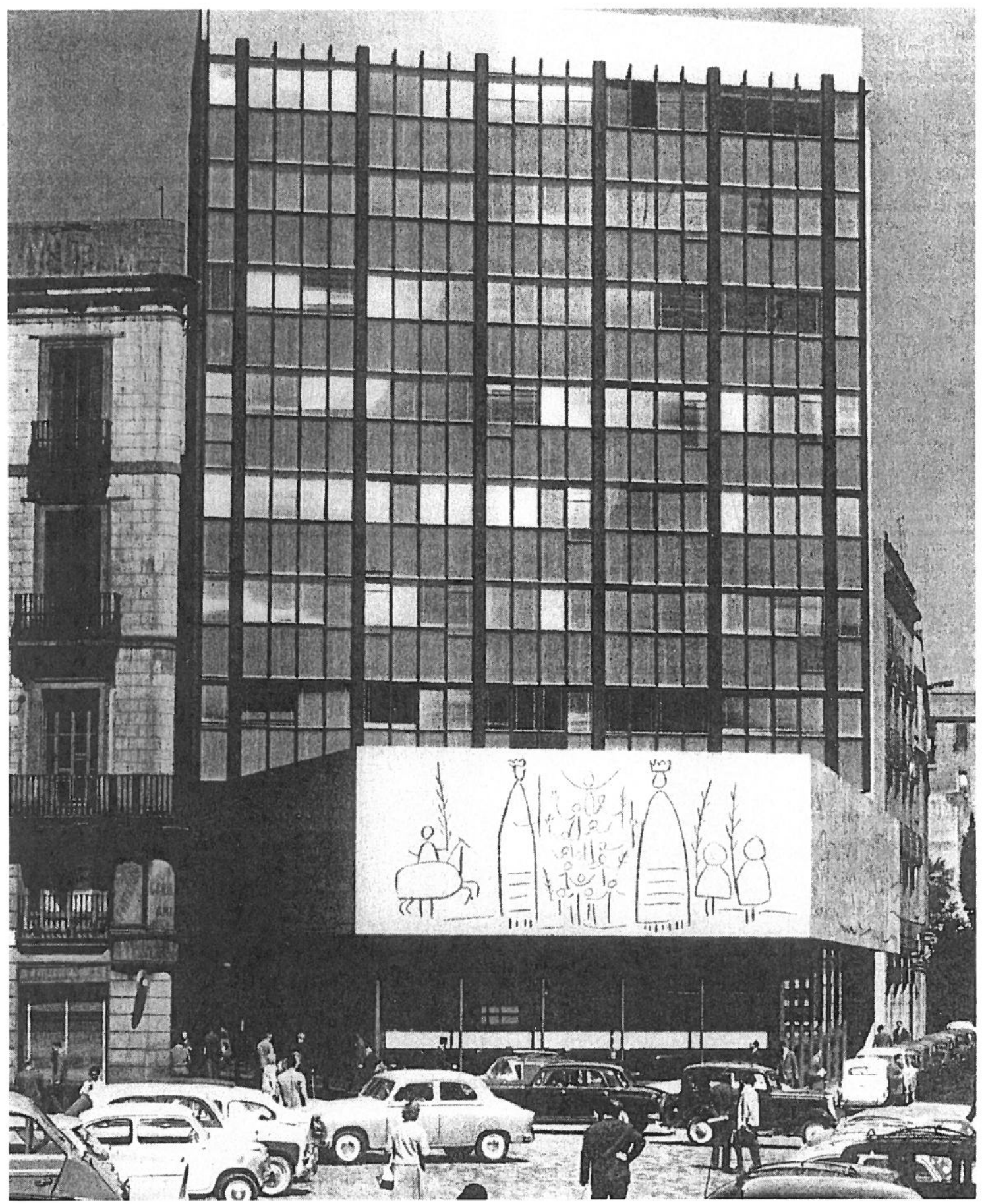

2.- Panel esgrafiado del chaflán de la Plaza Nueva. 


\section{Joan Bassegoda i Nonell}

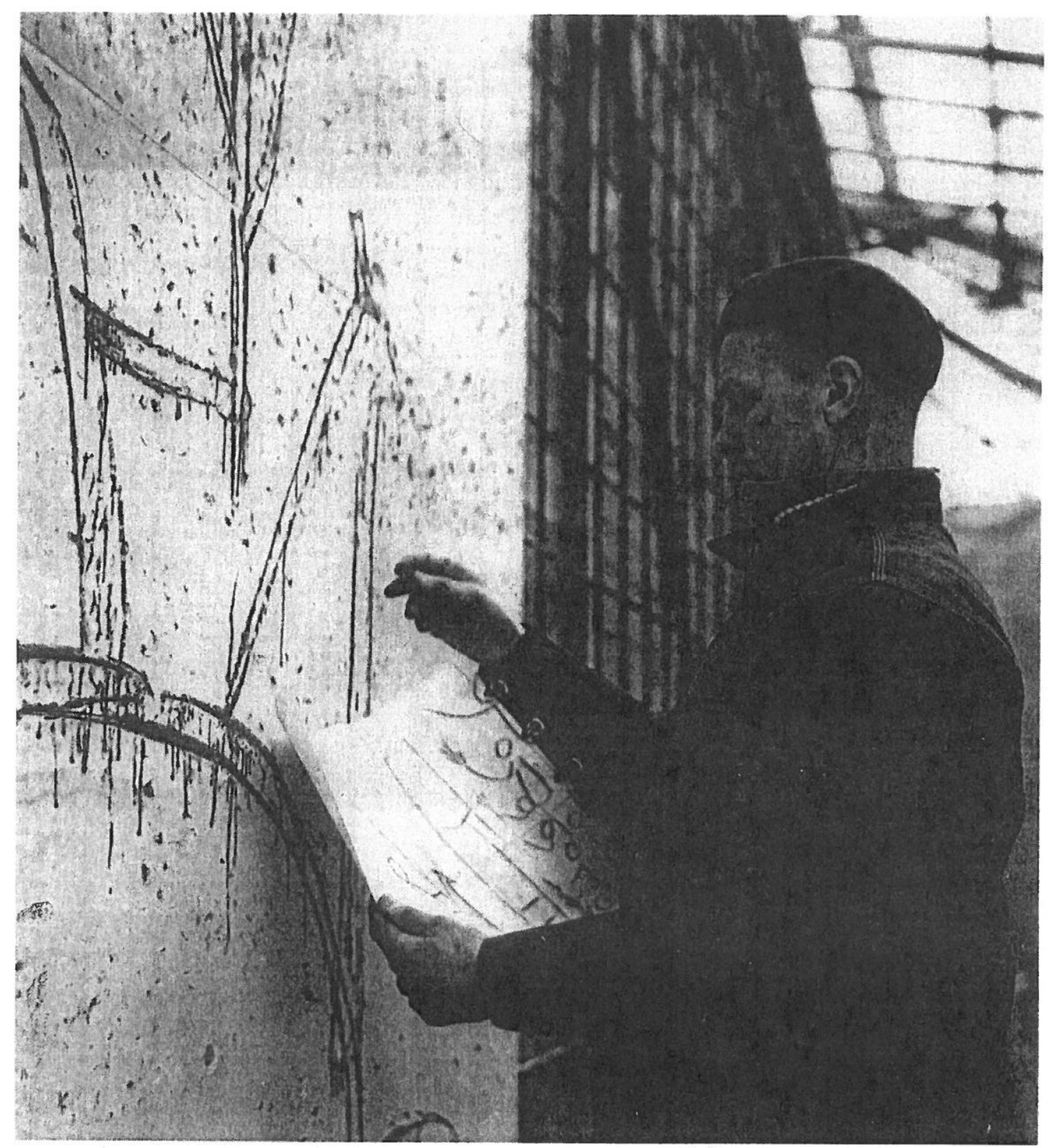

3.- Carl Nesjar retocando los estarcidos. 
La mayor obra de Picasso en Barcelona...

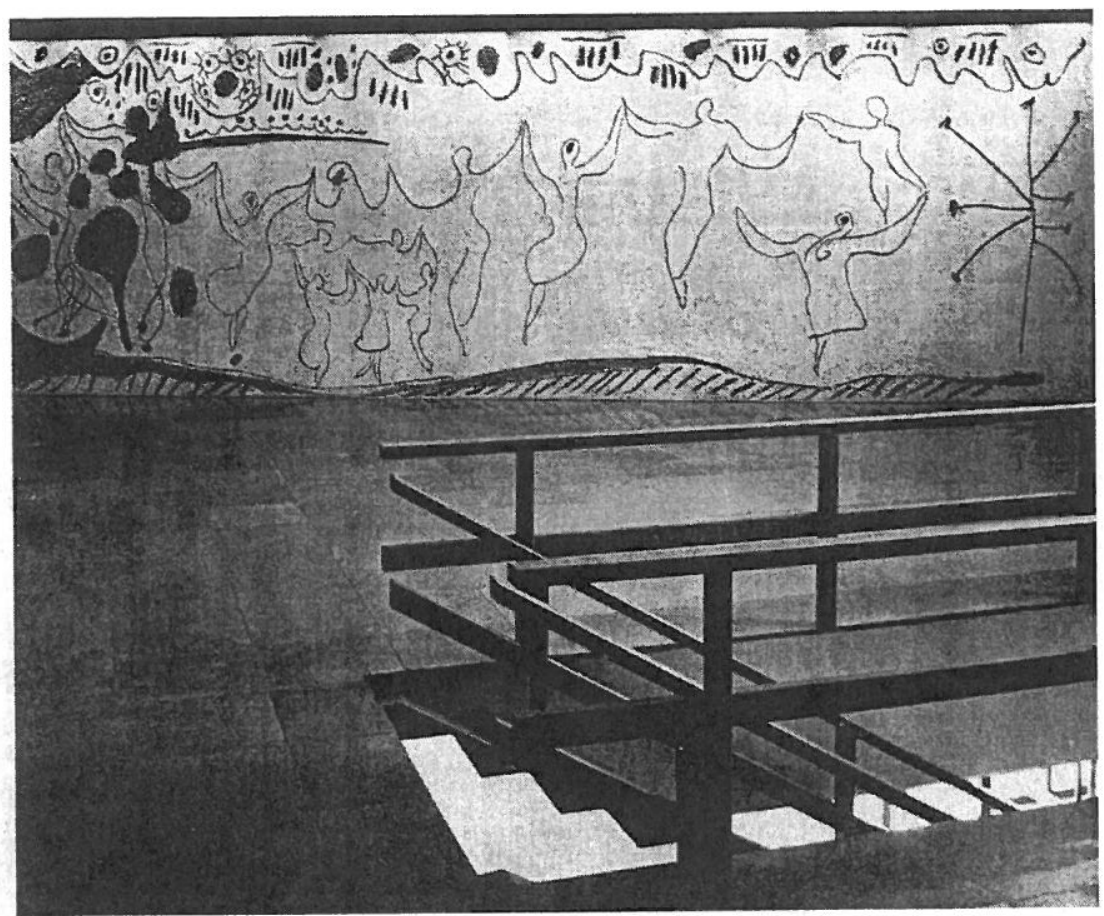

4.- Panel de la sardana en el muro anterior de la antesala del auditorio del Colegio de Arquitectos. Corresponde a la parte de la calle Capellans.

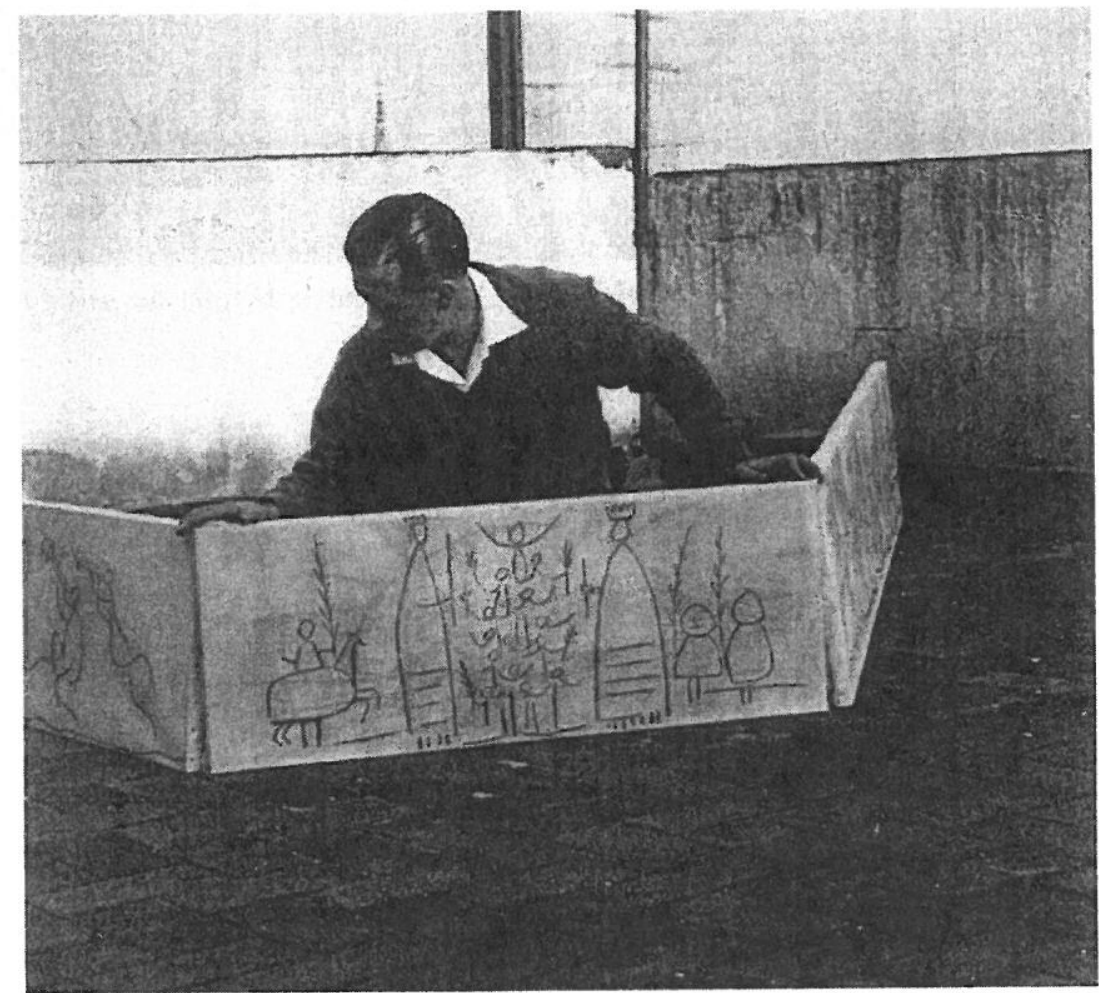

5.- Javier Busquets con los dibujos al carbón originales de Picasso sobre bastidores de madera y tela. 


\section{Joan Bassegoda i Nonell}

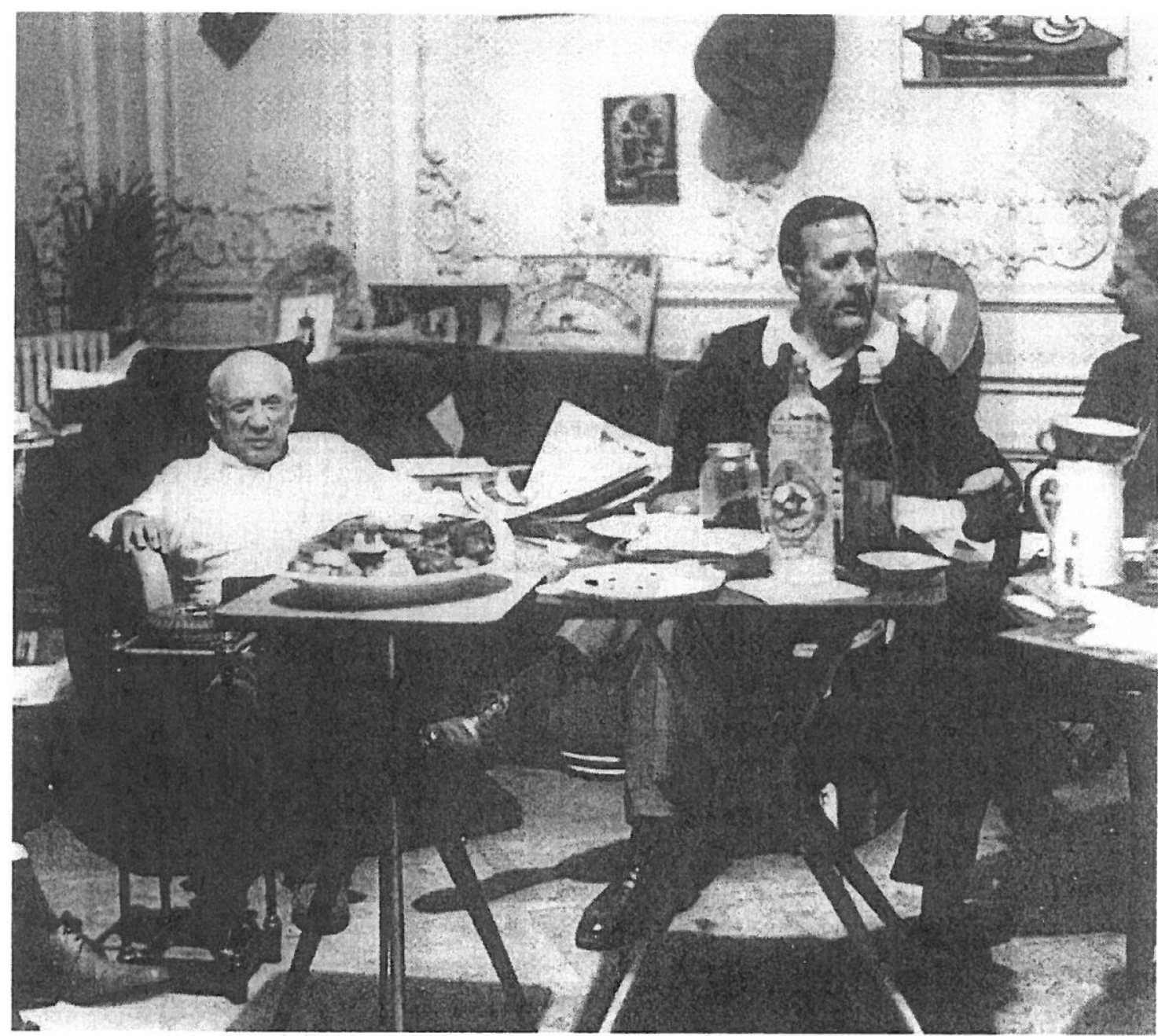

6.- Picasso y Javier Busquets en La Californie (1960). A destacar la botella de anis El Mono sobre la mesa. 